\title{
Patients' Preferences regarding Shared Decision- Making in the Treatment of Inflammatory Bowel Disease: Results from a Patient-Empowerment Study
}

\author{
Judith E. Baars ${ }^{a}$ Tineke Markus ${ }^{c}$ Ernst J. Kuipers ${ }^{a}$ b C. Janneke van der Woude ${ }^{a}$ \\ Departments of a Gastroenterology and Hepatology, and ${ }^{\mathrm{b}}$ Internal Medicine, Erasmus MC, Rotterdam, and \\ 'Dutch Patients' Association of Crohn's Disease and Ulcerative Colitis, Breukelen, The Netherlands
}

\section{Key Words}

Inflammatory bowel disease $\cdot$ Shared decision-making •

Patients' preferences

\begin{abstract}
Background: Shared decision-making is gaining favor in clinical practice, although the extent to which patients want to be involved in choosing their treatment varies substantially. Because data are lacking on the preferences of patients with chronic diseases such as inflammatory bowel disease (IBD), we wanted to assess IBD patients' preferences about being involved in such decisions. Methods: Adult IBD patients were asked to anonymously complete an online survey on their preferences. Non-parametric tests $\left(\chi^{2}\right)$ were used to determine the relationship between responses and respondents. Results: The questionnaire was completed by 1,067 patients, 617 with Crohn's disease and 450 with ulcerative colitis. Patients' mean age was 43 (SD 13.7) years; the majority were female $(66 \%)$. In total, 866 patients ( $81 \%)$ reported it as 'very important' to be actively involved in the decision-making process, and another 177 (17\%) rated it as 'quite important'. When asked how their treatment could be improved, 537 patients (50\%) wanted close, equitable collaboration with their physician. This preference was signifi-
\end{abstract}

cantly associated with a disease duration of $\leq 8$ years ( $p=$ 0.03 ). Gender and type of IBD were not significantly associated with patients' preferences. Conclusions: This study demonstrates IBD patients' desire to be actively involved in the decision-making process. Further research is needed on physicians' perspectives on shared decision-making, and on finding predictive factors for developing a model for shared decision-making in IBD.

Copyright $\odot 2010$ S. Karger AG, Basel

\section{Introduction}

Shared decision-making is increasingly advocated as an ideal model of treatment decision-making [1-3]. In this model the physician has the responsibility to inform the patients and give them advice, whereas the actual decisions on how to act on this information are made in collaboration between the patient and physician [4].

Patients and physicians vary substantially in the degree to which they are comfortable with patients' involvement in decision-making $[5,6]$. The literature available on patients' preferences of shared decision-making has mainly focused on healthy persons or restricted populations, especially cancer patients [7-11]. Other studies are

\section{KARGER}

Fax +4161306 1234

E-Mail karger@karger.ch

www.karger.com
(C) 2010 S. Karger AG, Basel

$0012-2823 / 10 / 0812-0113 \$ 26.00 / 0$

Accessible online at:

www.karger.com/dig
Judith E. Baars

Department of Gastroenterology and Hepatology

Erasmus MC, Postbus 2040, Room Ba 393

NL-3000 CA Rotterdam (The Netherlands)

Tel. +31 10703 2786, Fax +31 10703 5172,E-Mail j.baars@erasmusmc.nl 
limited by small sample sizes or hypothetical scenarios [12-14]. Patients' information needs and decision-making can change during treatment, as demonstrated in breast cancer patients [15]. Healthy persons' preferences can therefore not be extrapolated to sick patients who need medicinal treatment.

Patients with chronic diseases may have different preferences regarding shared decision-making than healthy patients who are put in a hypothetical scenario. A systematic review of the effects of shared decisionmaking suggested that shared decision-making is especially suitable for long-term decisions and/or in case of a chronic disease [16]. However, further data on the preferences of patients with inflammatory bowel disease (IBD) are lacking.

IBD is the heading for two major chronic gastrointestinal diseases of unknown origin: ulcerative colitis (UC) and Crohn's disease (CD). In 2004, as many as 1.4 million persons in the United States and 2.2 million persons in Europe suffered from these diseases [17]. The incidence of IBD has been increasing over the years, which for UC varies greatly between 0.5 and $24.5 / 10^{5}$ inhabitants, and for CD varies between 0.1 and $16 / 10^{5}$ inhabitants worldwide $[18,19]$. The prevalence rates of IBD reach up to $396 / 10^{5}$ inhabitants [19]. Patients with IBD have a decreased quality of life, both influenced by symptoms and treatments [20,21]. Several therapeutic strategies, including the wide use of immunosuppressants, have been advocated in the treatment of these chronic diseases, each with its own risks and benefits [22].

Patient-empowerment is becoming increasingly important in the management of chronic diseases [23]. This model posits that patients are responsible for their choices and also the consequences of their choices. As a result of empowerment, patients may develop a greater sense of self-efficacy regarding various disease and treatment-related behaviors, and may express changes in life priorities and values. Due to empowerment, patients are also expected to better self-manage not only their disease, but also their lives [24]. It has been suggested that patients show better adherence when they are actively involved in the decision-making process $[5,16]$. Non-adherence is an important reason for relapsing disease in IBD [25]. Shared decision-making can therefore be used to educate patients about the utmost importance of adherence to medication and the necessity to commit and follow-through on their treatment.

It is unknown to what extent IBD patients actually want to be involved in decision-making regarding the most appropriate therapeutic strategy for their disease.
The purpose of this patient-empowerment study was to assess IBD patients' preferences with regard to their involvement in the decision of treatment choices.

\section{Methods}

\section{Questionnaire}

A patient-empowerment study was performed in collaboration with the Dutch Patients' Association of Crohn's disease and Ulcerative Colitis (CCUVN). A questionnaire was developed by members of the CCUVN working in close collaboration with a panel of IBD patients not associated with the CCUVN. During several meetings, patients discussed the issues of shared decision-making and questioned to what extent they wanted to be involved in the decision-making about their treatment strategies. The questionnaire mirrors the outcome of these discussions. After the questionnaire had been framed, an independent physician advised the panel on the scientific and medical content of the questionnaire.

In close-ended questions, patients were asked how they assessed a possible active involvement in the decision-making of their own treatment. In open-ended questions patients were asked what they should know or receive from their treating physicians in order to be better treated for their disease. After pilot testing on a panel of IBD patients, the questionnaire was further optimized. This panel consists of IBD patients whose opinions are regularly solicited for such purposes and therefore have an extensive expertise on evaluating questionnaires. The questionnaire is listed in the appendix.

\section{CCUVN Respondents}

The definitive questionnaire was placed on the website of the CCUVN from December 2006 to January 2007. The CCUVN has approximately 10,250 members, of whom 9,509 have registered their gender and age. Of these 9,509 registered CCUVN members, $65 \%$ are female and $66 \%$ are $\leq 50$ years old. Adult IBD patients were asked to fill out the questionnaire anonymously.

A randomly selected group of patients from our outpatient IBD clinic was used to confirm the representativeness of the internet population. Patients were asked to fill out the questionnaire before they visited their physician and were assured their answers would stay anonymous. Patients who had already cooperated in the online questionnaire were excluded.

\section{Statistical Analysis}

Statistical analysis was performed using descriptive statistics and $\chi^{2}$ tests. Ordinal survey items were compared using nonparametric tests $\left(\chi^{2}\right)$. Groups were compared based on age, gender and duration of disease, which was subdivided into $\leq 8$ years of disease and $>8$ years of disease. The cutoff of 8 years concerning duration of disease was chosen by the panel of IBD patients. The patients decided to divide duration of disease into 4 categories $(0-2,3-8,9-15$, and $>15$ years). For statistical purposes this was combined in 2 groups, 'short duration of disease' and 'long duration of disease'. Mann-Whitney U tests were used to assess differences in responses among the online group and the outpatient clinic group. The statistical software SPSS version 15.0 for Windows was used for all statistical analyses. 
Table 1. Patient characteristics

\begin{tabular}{|c|c|c|}
\hline & Online group & $\begin{array}{l}\text { Outpatient } \\
\text { clinic group }\end{array}$ \\
\hline Number & 1,067 & 169 \\
\hline \multicolumn{3}{|l|}{ Disease } \\
\hline Crohn's disease & $617(58 \%)$ & $125(74 \%)$ \\
\hline Ulcerative colitis & $450(42 \%)$ & $41(24 \%)$ \\
\hline Unclassified colitis & - & $3(2 \%)$ \\
\hline Female gender & $703(66 \%)$ & $84(50 \%)$ \\
\hline Mean age $\pm S D$, years & $42.9 \pm 13.7$ & $38.7 \pm 14.4$ \\
\hline \multicolumn{3}{|l|}{ Duration of disease } \\
\hline $0-2$ years & $179(17 \%)$ & $22(13 \%)$ \\
\hline $3-8$ years & $313(29 \%)$ & $54(32 \%)$ \\
\hline $9-15$ years & $277(26 \%)$ & $43(25 \%)$ \\
\hline$>15$ years & $298(28 \%)$ & $50(30 \%)$ \\
\hline Decreased quality of life & $531(50 \%)$ & $100(59 \%)$ \\
\hline Member CCUVN & $1,001(94 \%)$ & $61(36 \%)$ \\
\hline
\end{tabular}

\section{Results}

\section{Study Population}

In total, 1,093 patients filled out the questionnaire online. Twenty-six patients were excluded from analysis due to lack of information on their type of IBD $(n=24)$ or on their gender $(n=2)$. Patient characteristics are shown in table 1 . Of the 1,067 patients included in the analysis, 617 had CD (58\%) and 450 had UC (42\%). The mean age of patients was 42.9 (SD 13.7) years old, the duration of disease was $>8$ years in 575 patients (54\%), and 703 patients (66\%) were female.

The CCUVN has approximately 10,250 members, of whom 9,509 have registered their gender and age. Of all members, $10 \%$ filled out our questionnaire which, in addition, is fully representative of all CCUVN members with regard to age and gender. Of the 9,509 registered CCUVN members, $65 \%$ are female and $66 \%$ are $\leq 50$ years old, which is comparable to the demographics in our group (66\% female; mean age 43 years).

\section{Patients' Satisfaction with Current Practice}

In total, 980 patients (92\%) were satisfied or very satisfied with the extent to which their physician currently involves them in the decision-making concerning their medical treatment (table 2). With regard to the time and attention given by the physician during visits to the outpatient clinic, 949 patients (89\%) were at least 'satisfied'. The current medical treatment as prescribed by the treating physician could be improved according to 216 pa-
Table 2. Patients' satisfaction concerning current treatment in the online group compared with the outpatient clinic group

\begin{tabular}{lccc}
\hline & $\begin{array}{l}\text { Online } \\
\text { group }\end{array}$ & $\begin{array}{c}\text { Outpatient } \\
\text { clinic group }\end{array}$ & p value \\
\hline Satisfaction with current & involvement in treatment? & \\
Very satisfied & $665(62 \%)$ & $110(65 \%)$ & \\
Satisfied & $315(30 \%)$ & $42(25 \%)$ & \\
Dissatisfied & $54(5 \%)$ & $8(5 \%)$ & n.s. \\
Very dissatisfied & $33(3 \%)$ & $2(1 \%)$ & \\
No answer given & - & $7(4 \%)$ & \\
\hline Satisfaction time and attention from physician during clinic visit? & & \\
Very satisfied & $674(63 \%)$ & $118(70 \%)$ & \\
Satisfied & $275(26 \%)$ & $38(22.5 \%)$ & \\
Dissatisfied & $90(8 \%)$ & $10(5.9 \%)$ & 0.04 \\
Very dissatisfied & $28(3 \%)$ & $1(1 \%)$ & \\
No answer given & - & $2(1 \%)$ & \\
\hline Could the current medical treatment prescribed by physician be \\
improved? & & & \\
Yes & $216(20 \%)$ & $33(20 \%)$ & \\
No & $851(80 \%)$ & $120(71 \%)$ & n.s. \\
No answer given & - & $16(10 \%)$ & \\
\hline
\end{tabular}

tients (20\%). Patients' suggestions to improve current treatment are listed in table 3.

\section{Active Involvement in Decision-Making Is Very \\ Important for IBD Patients}

Patients' assessments of the involvement in the decision-making are shown in figure 1 . In total, 866 patients $(81 \%)$ called it 'very important' to be actively involved in the decision-making regarding their medical treatment options. Another 177 patients (17\%) rated active involvement in this decision process as 'quite important'.

\section{Patients Require Close Collaboration with Physicians to Improve Treatment Regimen}

When asked what is important for patients to be better treated for their disease, 537 patients (50\%) requested a close-equitable collaboration with their physician (table 3). Duration of disease was significantly associated with this response: 307 of 575 patients with $\leq 8$ years of disease (53\%) against 230 of 492 patients (47\%) with $>8$ years of disease $(\mathrm{p}=0.03)$ wanted good collaboration with the physician to be based on equivalence (fig. 2). In answer to this same question, 289 patients (27\%) suggested a checklist to fill out in order to improve their current treatment regimen, again in close collaboration with their physician. This was also significantly associated 
Table 3. Patients' suggestions to improve current treatment in the online group $\mathrm{n}$

Number

1,067

$537(50 \%)$

$496(47 \%)$

$427(40 \%)$

$579(54 \%)$

$289(27 \%)$

$232(22 \%)$

$384(36 \%)$

$324(30 \%)$

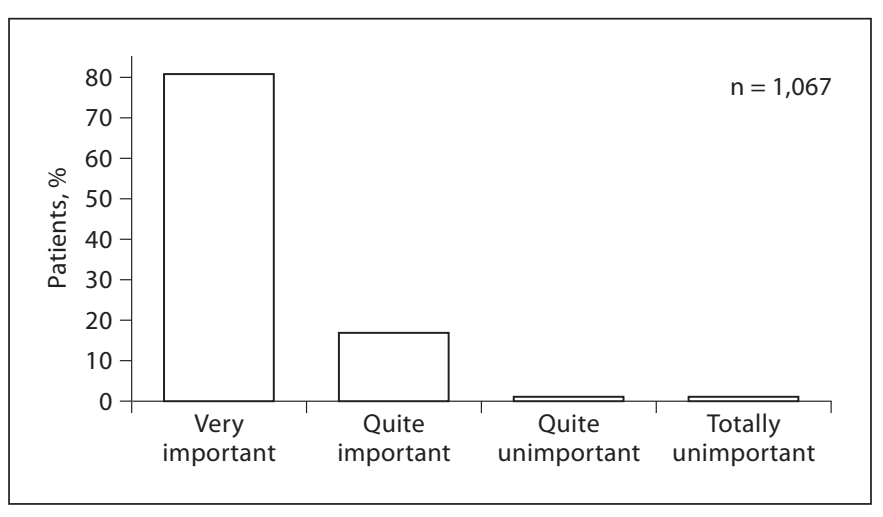

Fig. 1. IBD patients' assessments of shared decision-making.

with the duration of disease: $24 \%(140 / 575)$ of the patients with a short duration of disease ( $\leq 8$ years) against $30 \%$ (149/492) of the patients with a long duration of disease ( $>8$ years) suggested this option of a checklist $(\mathrm{p}=0.03)$. In total, 579 patients (54\%) wanted more information on new medication options in order to improve their treatment; 496 patients (47\%) wanted more knowledge about the cause of their disease, and 579 patients (54\%) wanted more general information on their disease.

In none of the questions were gender and type of IBD significantly associated with patients' assessments of shared decision-making.

\section{Shared Decision-Making among Patients in the Outpatient Clinic Group}

In total, 169 patients from our outpatient IBD clinic completed the questionnaire: 125 had CD (74\%), 41 had UC (24\%), and 3 patients had unclassified colitis (2\%).

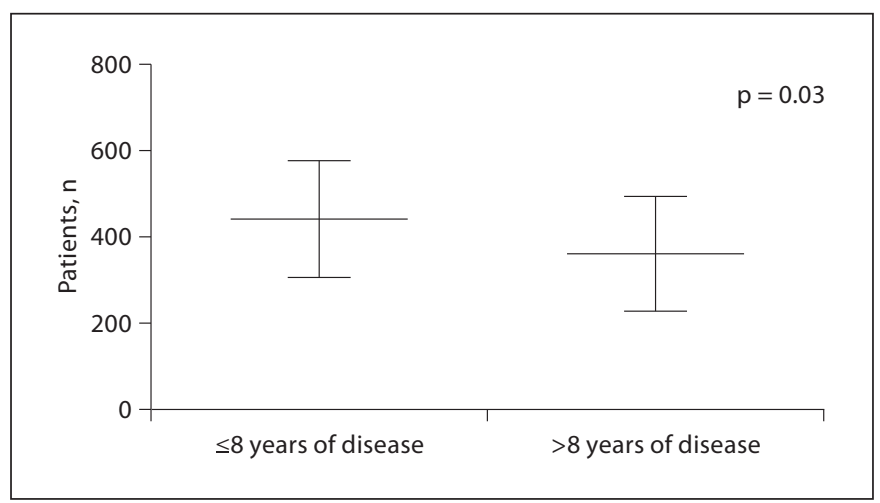

Fig. 2. IBD patients' demands for improving treatment: good collaboration with physician, based on equivalence.

The mean age of patients was 38.7 (SD 14.4) years old, duration of disease was $>8$ years in 93 patients (55\%), and 84 patients (50\%) were female. Of the outpatient clinic group, 61 patients (36\%) were member of the CCUVN. Patient characteristics are shown in table 1. Patients' satisfaction concerning current treatment in the outpatient clinic group are listed in table 2. Compared with patients in the online group, IBD patients in the outpatient clinic group are more satisfied with the time and attention that is given to them during their visit to the IBD clinic ( $\mathrm{p}=$ 0.04). Both groups are equally satisfied with their current treatment and their involvement in this treatment.

Patients' preferences regarding shared decision-making are demonstrated and compared with the preferences of those in the online group in table 4. In total, 147 patients $(87 \%)$ called it 'very important' to be actively involved in the decision of their medical treatment options. Another 18 patients (11\%) rated active involvement in this 
Table 4. Patients' preferences on shared decision-making in the online group and outpatient clinic group

\begin{tabular}{lccc}
\hline & $\begin{array}{l}\text { Online } \\
\text { group }\end{array}$ & $\begin{array}{l}\text { Outpatient } \\
\text { clinic group }\end{array}$ & p value \\
\hline Overall assessment of shared decision-making & \\
Very important & $866(81 \%)$ & $147(87 \%)$ & \\
Quite important & $177(17 \%)$ & $18(11 \%)$ & \\
Quite unimportant & $13(1 \%)$ & $2(1 \%)$ & 0.003 \\
Totally unimportant & $11(1 \%)$ & - & \\
No answer given & - & $2(1 \%)$ & \\
Requesting a close, equitable collaboration \\
with their physician & $537(50 \%)$ & $112(67 \%)$ & $<0.001$ \\
\hline
\end{tabular}

decision process as 'quite important'. This percentage was even higher compared to the online group $(p=0.03)$. A close equitable collaboration with their physician was requested by 112 patients (67\%). This percentage was significantly higher compared to the online group $(\mathrm{p}<$ $0.001)$.

\section{Discussion}

This large survey demonstrates that a significant proportion of patients with IBD prefer active involvement in the decision-making process of the treatment of their disease. Half of these patients want an equitable relationship with their physician to improve their treatment regimen, and more than half of all patients want to be better informed about their disease and new medication options. Patients with a shorter duration of disease report preferring more involvement in the decision-making process. This can be explained by the fact that these patients are more often in the active phase of their disease and therefore need frequent adjustments in their treatment strategy [26].

Patient participation in decision-making has been advocated for many reasons. Patients who are active participants in the process of their care, e.g. asking questions, expressing their opinions and stating preferences regarding treatment, have measurably better health outcomes than patients who do not participate in the decision-making $[2,5,13,15,27]$. Patients who feel that they have participated in decision-making are also more likely to follow through on those decisions than patients who do not participate in this process. This is very important in a chronic disease such as IBD, since non-adherence to therapy is one of the many possible reasons for relapsing disease [25]. Moreover, non-adherence is in general associated with higher healthcare costs and in the case of 5ASA medication, non-adherence may even be associated with a higher risk of colorectal cancer [28]. Improving adherence is therefore of great importance for improving health outcomes in IBD.

Since shared decision-making is based on collaboration between patients and doctors, not only patients' perspectives are of interest for shared decision-making, but doctors' perspectives and preferences should be included as well. However, there are relatively few studies on physicians' preferences for decision-making [29-31]. A crosssectional survey of a nationally representative sample of US physicians demonstrated that $75 \%$ of the physicians $(780 / 1,050)$ preferred to share the decision-making with their patients $[2,30]$. Nonetheless, data on preferences of doctors treating especially chronically ill patients, such as IBD patients, are lacking.

Another factor that involves shared decision-making is the working knowledge base which is influenced by research evidence and evaluation and synthesizing of the evidence. In a chronic disease such as IBD, patients need to be treated with specific medication which has to be taken consequently and most often has to be continued indefinitely. Each kind of treatment has its own possible benefits, risks and side effects, and there is considerable variability in the progression of the disease in individual patients and patients' individual responses to medication. This complicates the implementation of shared decision-making in the treatment of IBD. Further research on predictive factors for individual response to therapies is necessary to develop a model for shared decision-making in IBD. Based on these predictive factors, not only physicians but also patients should be able to decide which side effects and treatment-associated risks they are willing to accept for a possible treatment benefit [32]. In shared decision-making, information on treatment options is exchanged and patients are involved in the final decision.

Internet surveys are generally limited by their lack of information on response rates and generalizability. The CCUVN has approximately 10,250 members, of whom 9,509 have registered their gender and age. Of all members, only $10 \%$ filled out our questionnaire, which was however fully representative for all CCUVN members with regard to age and gender. Additional patient characteristics of the total CCUVN population are unknown and the representativeness of our respondents based on 
the type of IBD cannot be verified. However, type of IBD was not significantly associated with patients' preferences of shared decision-making.

We recognize that our respondents are all CCUVN members and therefore are not representative of all Dutch IBD patients. Therefore a control group of IBD patients from an outpatient IBD practice was used. These patients showed even a higher preference rate for shared decisionmaking and therefore verified the preferences from the online population.

Another limitation of our study is that information is lacking on current clinical practice with regard to shared decision-making. Our aim was solely to assess patients' preferences on decision-making and the extent to which they wish to be involved in this process. Our study presents a new focus to improve standard care and to be able to develop a model to implement shared decision-making in clinical practice in the future.

This study is a patient-empowerment study and uses a non-validated questionnaire which was developed by IBD patients to obtain pure information on patients' preferences. Using a patient-based questionnaire distributed through the internet, we were able to reach a large nationwide patient group while obtaining information anonymously without intentional or unintentional interference by healthcare providers. A group from our outpatient IBD clinic was used as control group to verify the results. This group confirmed the need for shared decision-making in IBD patients.

In conclusion, this patient-empowerment study demonstrates that IBD patients prefer active involvement in the decision-making process concerning the treatment of their disease. This is of importance to respect patients as persons, but above all to improve health outcomes. Limited data are available on factors influencing shared decision-making in IBD. It is therefore a challenge to implement shared decision-making in the healthcare of IBD in the future. Further research is needed on physicians' perspectives on shared decision-making and on developing a model to implement shared decision-making in clinical practice using predictive factors. Nonetheless, our results demonstrate that most IBD patients are ready to implement shared decision-making to improve their treatment strategy.
Appendix: The questionnaire

What type of inflammatory bowel disease (IBD) do you have?
(a) Crohn's disease
(c) Unclassified colitis
(b) Ulcerative colitis

How long has it been since you were diagnosed with IBD?
(a) $0-2$ years
(c) 9-15 years
(b) 3-8 years
(d) longer than 15 years

What is your gender?
(a) Male
(b) Female

How old are you? years old

Are you a member of the Dutch Crohn's and Colitis organization (CCUVN)?
(a) Yes
(b) $\mathrm{No}$

If you think about the decisions your physician makes concerning your medical treatment, how satisfied are you with the extent to which your physician involves you in these decisions?
(a) Very satisfied
(c) Dissatisfied
(b) Satisfied
(d) Very dissatisfied

How important is it for you that your physician involves you in the decisions concerning your medical treatment?
(a) Very important
(c) Quite unimportant
(b) Quite important
(d) Totally unimportant

How satisfied are you with the time and attention that your physician spends on you during your visits to the outpatient clinic?
(a) Very satisfied
(c) Dissatisfied
(b) Satisfied
(d) Very dissatisfied

Do you think that your medical treatment prescribed by your physician could be improved?
(a) Yes
(b) No

How could the treatment prescribed by your physician be improved?

What does a patient like you need to know/receive to be able to get better treatment for your disease (multiple answers may be given)

(a) More knowledge of the cause of my disease

(b) More knowledge of my disease in general

(c) More knowledge of any new medications (and when they are in particular suitable)

(d) A checklist to fill out, so my doctor and I can improve my treatment in close consultation

(e) More information on what my doctor needs to be able to improve my treatment

(f) A close collaboration with my doctor based on equivalence

(g) Information on websites, flyers and current research

(h) To get in touch with fellow sufferers or hands-on experts

(i) Nothing

Do you have any suggestions to improve collaboration with your treating physician? 


\section{References}

$\checkmark 1$ Charles C, Gafni A, Whelan T: Shared decision-making in the medical encounter: what does it mean? (or it takes at least two to tango). Soc Sci Med 1997;44:681-692.

-2 Murray E, Pollack L, White M, Lo B: Clinical decision-making: Patients' preferences and experiences. Patient Educ Couns 2007;65: 189-196.

>3 Légaré F, Ratté S, Gravel K, Graham ID: Barriers and facilitators to implementing shared decision-making in clinical practice: update of a systematic review of health professionals' perceptions. Patient Educ Couns 2008; 73:526-535.

$\checkmark 4$ Siegel CA: Embracing the internet for progress in shared decision-making. Inflamm Bowel Dis 2007;13:1579-1580.

5 Kaplan SH, Greenfield S, Gandek B, Rogers WH, Ware JE Jr: Characteristics of physicians with participatory decision-making styles. Ann Intern Med 1996;124:497-504.

$\checkmark 6$ Levinson W, Kao A, Kuby A, Thisted RA: Not all patients want to participate in decision making. A national study of public preferences. J Gen Intern Med 2005;20:531-535.

7 Wallberg B, Michelson H, Nystedt M, Bolund C, Degner LF, Wilking N: Information needs and preferences for participation in treatment decisions among Swedish breast cancer patients. Acta Oncol 2000;39:467476.

8 Stewart DE, Wong F, Cheung AM, Dancey J, Meana M, Cameron JI, McAndrews MP, Bunston T, Murphy J, Rosen B: Information needs and decisional preferences among women with ovarian cancer. Gynecol Oncol 2000;77:357-361.

-9 Beaver K, Jones D, Susnerwala S, Craven O, Tomlinson M, Witham G, Luker KA: Exploring the decision-making preferences of people with colorectal cancer. Health Expect 2005;8:103-113.

$>10$ Wong F, Stewart DE, Dancey J, Meana M, McAndrews MP, Bunston T, Cheung AM: Men with prostate cancer: influence of psychological factors on informational needs and decision making. J Psychosom Res 2000; 49:13-19.
11 Degner LF, Sloan JA: Decision making during serious illness: what role do patients really want to play? J Clin Epidemiol 1992;45: 941-950.

12 Guadagnoli E, Ward P: Patient participation in decision-making. Soc Sci Med 1998;47: 329-339.

13 Fraenkel L, McGraw S: Participation in medical decision making: the patients' perspective. Med Decis Making 2007;27:533-538.

14 McKinstry B: Do patients wish to be involved in decision making in the consultation? A cross sectional survey with video vignettes. BMJ 2000;321:867-871.

15 Vogel BA, Bengel J, Helmes AW: Information and decision making: patients' needs and experiences in the course of breast cancer treatment. Patient Educ Couns 2008;71:79-85.

16 Joosten EA, Fuentes-Merillas L, de Weert GH, Sensky T, van der Staak CP, de Jong CA: Systematic review of the effects of shared decision-making on patient satisfaction, treatment adherence and health status. Psychother Psychosom 2008;77:219-226.

17 Loftus EV Jr: Clinical epidemiology of inflammatory bowel disease: incidence, prevalence, and environmental influences. Gastroenterology 2004;126:1504-1517.

18 Jacobsen BA, Fallingborg J, Rasmussen $\mathrm{HH}$, Nielsen KR, Drewes AM, Puho E, Nielsen GL, Sorensen HT: Increase in incidence and prevalence of inflammatory bowel disease in northern Denmark: a population-based study, 1978-2002. Eur J Gastroenterol Hepatol 2006; 18:601-606.

19 Lakatos PL: Recent trends in the epidemiology of inflammatory bowel diseases: up or down? World J Gastroenterol 2006;12:61026108.

20 Larsson K, Loof L, Ronnblom A, Nordin K: Quality of life for patients with exacerbation in inflammatory bowel disease and how they cope with disease activity. J Psychosom Res 2008;64:139-148.

21 Vidal A, Gomez-Gil E, Sans M, Portella MJ, Salamero M, Pique JM, Panes J: Health-related quality of life in inflammatory bowel disease patients: the role of psychopathology and personality. Inflamm Bowel Dis 2008; 14:977-983.

-22 Cosnes J, Nion-Larmurier I, Beaugerie L, Afchain P, Tiret E, Gendre JP: Impact of the increasing use of immunosuppressants in Crohn's disease on the need for intestinal surgery. Gut 2005;54:237-241.
23 Meyer C, Muhlfeld A, Drexhage C, Floege J, Goepel E, Schauerte P, Kelm M, Rassaf T: Clinical research for patient empowerment - a qualitative approach on the improvement of heart health promotion in chronic illness. Med Sci Monit 2008;14:CR358-CR365.

$\checkmark 24$ Aujoulat I, d'Hoore W, Deccache A: Patient empowerment in theory and practice: polysemy or cacophony? Patient Educ Couns 2007;66:13-20.

25 Kane SV, Cohen RD, Aikens JE, Hanauer SB: Prevalence of nonadherence with maintenance mesalamine in quiescent ulcerative colitis. Am J Gastroenterol 2001;96:29292933.

26 Cosnes J, Cattan S, Blain A, Beaugerie L, Carbonnel F, Parc R, Gendre JP: Long-term evolution of disease behavior of Crohn's disease. Inflamm Bowel Dis 2002;8:244-250.

27 Ryan J, Sysko J: The contingency of patient preferences for involvement in health decision making. Health Care Manage Rev 2007; 32:30-36.

28 Kane S, Huo D, Aikens J, Hanauer S: Medication nonadherence and the outcomes of patients with quiescent ulcerative colitis. Am J Med 2003; 114:39-43.

-29 Pieterse AH, Baas-Thijssen MC, Marijnen CA, Stiggelbout AM: Clinician and cancer patient views on patient participation in treatment decision-making: a quantitative and qualitative exploration. $\mathrm{Br} \mathrm{J}$ Cancer 2008;99:875-882.

30 Murray E, Pollack L, White M, Lo B: Clinical decision-making: physicians' preferences and experiences. BMC Fam Pract 2007;8:10.

31 McGuire AL, McCullough LB, Weller SC, Whitney SN: Missed expectations? Physicians' views of patients' participation in medical decision-making. Med Care 2005; 43:466-470.

32 Baars JE, Siegel CA, Kuipers EJ, van der Woude CJ: Patient's perspectives important for early anti-tumor necrosis factor treatment in inflammatory bowel disease. Digestion 2009;79:30-35. 